\title{
Comparison of DFT Methods for the Investigation of the Reduction Mechanisms of Aromatic Nitro- and Nitroso Compounds
}

\author{
Marko Tomin, ${ }^{1}$ Igor Rončević, ${ }^{2}$ Zlatko Mihalić2*
}

\author{
1 Ruđer Bošković Institute, Bijenička cesta 54, HR-10000 Zagreb, Croatia \\ 2 Faculty of Science, University of Zagreb, Horvatovac 102A, HR-10000 Zagreb, Croatia \\ * Corresponding author's e-mail address: mihalic@chem.pmf.hr \\ RECEIVED: June 23, 2015 * REVISED: January 7, 2016 * ACCEPTED: January 7, 2016
}

\begin{abstract}
The main goal of this paper is to find an adequate level of theory for the computational investigation of the reduction mechanisms of aromatic nitro- and nitroso compounds. To this end, five standard reduction potentials of nitro- and nitrosobenzene in three different solvents and four $\mathrm{p} K_{\mathrm{a}}$ values of species involved in the mechanism were compared with the values calculated at different DFT and CBS-X levels of theory. Out of fourteen tested functionals, five showed good linear correlation between calculated and experimental $\Delta_{r} G^{\circ}$ values. However, at all explored levels of theory, the calculated $\Delta_{r} G^{\circ}$ values systematically deviate from the experimental ones, indicating the necessity of better description of solvation effects for charged species, possibly via a cluster-continuum approach.
\end{abstract}

Keywords: aromatic nitro compounds, reduction mechanism, DFT calculations, solvation.

\section{INTRODUCTION}

$\mathbf{N}$ ITROBENZENE and its derivatives have an important role in chemical and pharmaceutical industry. An estimated $95 \%$ of produced nitrobenzene undergoes reduction into aniline during the manufacture of dyes, pesticides, explosives and pharmaceuticals ${ }^{[1]}$ Since both nitrobenzene and its reduction intermediates are much more toxic than the amine product, ${ }^{[2,3]}$ a detailed understanding of the reduction mechanism is of great environmental importance.

Nitrobenzene (1) undergoes reduction via $\mathrm{N}, \mathrm{N}$-dihydroxyaniline (2) to nitrosobenzene (3), which is immediatelly converted to phenylhydroxylamine (4). Hydroxylamine can be isolated or in next step reduced to amine (5). The reaction is often accompanied by formation of dimerization products, which has been the focus of many recent studies. ${ }^{[4-7]}$

The reduction of aromatic nitro compounds has been extensively studied using spectroscopic, electrochemical and, in recent years, computational approaches. ${ }^{[8-14]}$ Although the available data strongly suggests that the reduction mechanism includes free radicals, its detailes, with identification and characterization of all involved species, have not unequivocally been established.

The main goal of this paper is to find a level of theory that can be used for not just the first elementary step of the reduction - a single electron transfer to nitrobenzene molecule - but also for the full computational investigation of this and similar reaction mechanisms. Our intention is to identify all possible participating species and viable

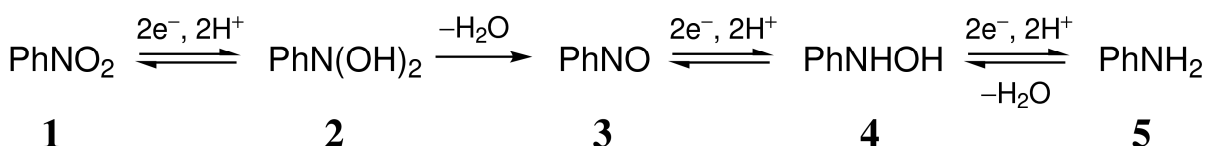

Scheme 1. Reduction mechanism of nitrobenzene. 
elementary steps. An ideal level of theory should be capable of correctly predicting properties of very different species, closed- and open-shell ones, neutral and charged, as well as correctly reproducing the solvation effects.

\section{COMPUTATIONAL METHODS}

The available experimental data pertinent to these reactions are standard reduction potentials obtained by cyclic voltammetry. Accurate modeling of reduction potentials has traditionally been a highly challenging task. ${ }^{[15-17]}$ However, the advent of new DFT methods and solvation models has warranted an increase in both the accuracy and the affordability of such a calculations. The common approach is based on the calculation of standard Gibbs energies of both the oxidized and the reduced species, i.e. the electron affinity, and its comparison against a reference reaction. The Faraday's Law allows conversion of standard Gibbs energies to electrode potentials and vice versa:

$$
E_{\text {red }}^{\circ}(v s . \text { ref })=-\frac{\Delta_{\text {red }} G^{\circ}(v s . \text { ref })}{n F}
$$

No consensus regarding the best computational method for modeling standard reduction potentials exists. For the reduction of aromatic nitro compounds, several different functionals were used, with basis sets ranging from 6-31G(d) to aug-cc-pVTZ. Leszczynski et al. calculated reduction potentials of nitrobenzenes against standard hydrogen electrode (SHE) as a reference and reported a MUE of $0.07 \mathrm{~V}(1.8 \mathrm{kcal} / \mathrm{mol})$ at mPWB1K/aug-cc-pVTZ level of theory using the PCM solvation model. ${ }^{[18]}$ A similar method was employed by Zhu and Wang for the modeling of various quinones in acetonitrile and DMSO. ${ }^{[19]} \mathrm{A}$ standard deviation from experimental data of $0.1 \mathrm{~V}(2.5 \mathrm{kcal} / \mathrm{mol})$ was achieved with the B3LYP/aug-cc-pVDZ model.

To find the DFT level of theory capable of modeling wider range of species included in the target mechanism, we decided to test various functionals against existing experimental data. Six model reduction reactions were the nitrobenzene one-electron reduction in water, DMF and acetonitrile, the nitrosobenzene one-electron reduction in acetonitrile and dimethylsulfoxide, and two-electron, twoproton reduction of nitrosobenzene to phenylhydroxyamine (reactions I-VI, Table 1). ${ }^{[20-27]}$

Standard reduction potentials measured relative to saturated calomel (SCE) or $\mathrm{Ag} \mid \mathrm{AgCl}$ reference electrodes were converted to standard reduction potentials relative to SHE by adding to them 0.2444 or $0.197 \mathrm{~V}$, respectively. To convert standard potentials reported relative to SHE to standard Gibbs energies, the absolute value of $E^{\circ}(\mathrm{SHE})$ of $4.281 \mathrm{~V}$ recommended by Isse and Gennaro ${ }^{[28]}$ was used.

In the model reactions set we also included four protonation/deprotonation equilibria of species known to take part in the mechanism (reactions VII-X, Table 1). The experimental $\mathrm{p} K_{\mathrm{a}}$ values of $\mathrm{PhNO}_{2} \mathrm{H}^{\circ}, \mathrm{PhNOH}^{\circ}, \mathrm{PhNOH}^{+}$and $\mathrm{PhNH}_{3}{ }^{+}$were converted to the corresponding $\Delta_{\mathrm{r}} \mathrm{G}^{\circ}$ values using the formula

$$
\Delta_{\mathrm{r}} G^{\circ}=\mathrm{p} K_{a} R T \ln 10
$$

In order to compute standard Gibbs energies of examined species by a DFT approach, we performed their solution-phase geometry optimizations and vibrational frequency calculations using SMD continuum method. SMD was chosen because of its high reliability for thermochemical data and near-universal applicability for various combinations of solutes, solvents and levels of theory. ${ }^{[29]}$

Table 1. Model reactions used in this paper, with corresponding experimental standard reduction potentials $\left(E^{\circ}\right)$ or $p K_{\mathrm{a}}$ values

\begin{tabular}{|c|c|c|c|c|c|c|}
\hline & Reaction & Solvent & Property & Value & Ref. & $\Delta_{r} G_{\exp }^{\circ}$ \\
\hline 1 & $\mathrm{PhNO}_{2}+\mathrm{e}^{-} \rightleftarrows \mathrm{PhNO}_{2} \cdot-$ & DMF & $E^{\circ}(\mathrm{SCE})$ & $-1.39 \mathrm{~V}$ & 20 & 26.42 \\
\hline$\|$ & $\mathrm{PhNO}_{2}+\mathrm{e}^{-} \rightleftarrows \mathrm{PhNO}_{2}^{\cdot-}$ & $\mathrm{MeCN}$ & $E^{\circ}(\mathrm{SCE})$ & $-1.36 \mathrm{~V}$ & 20 & 25.73 \\
\hline III & $\mathrm{PhNO}_{2}+\mathrm{e}^{-} \rightleftarrows \mathrm{PhNO}_{2}^{-}$ & $\mathrm{H}_{2} \mathrm{O}$ & $E^{\circ}(\mathrm{SHE})$ & $-0.485 \mathrm{~V}$ & 21 & 11.18 \\
\hline IV & $\mathrm{PhNO}+\mathrm{e}^{-} \rightleftarrows \mathrm{PhNO} \cdot-$ & DMSO & $E^{\circ}(\mathrm{AgCl})$ & $-0.770 \mathrm{~V}$ & 22 & 13.20 \\
\hline $\mathrm{v}$ & $\mathrm{PhNO}+\mathrm{e}^{-} \rightleftarrows \mathrm{PhNO} \cdot-$ & $\mathrm{MeCN}$ & $E^{\circ}(\mathrm{AgCl})$ & $-0.835 \mathrm{~V}$ & 22 & 14.71 \\
\hline $\mathrm{VI}$ & $\mathrm{PhNO}+2 \mathrm{e}^{-}+2 \mathrm{H}^{+} \rightleftarrows \mathrm{PhNHOH}$ & $\mathrm{H}_{2} \mathrm{O}$ & $E^{\circ}(\mathrm{SCE})$ & $0.305 \mathrm{~V}$ & 23 & -25.34 \\
\hline VII & $\mathrm{PhNHO}^{+} \rightleftarrows \mathrm{PhNO}+\mathrm{H}^{+}$ & $\mathrm{H}_{2} \mathrm{O}$ & $\mathrm{p} K_{\mathrm{a}}$ & -4.9 & 24 & -6.68 \\
\hline VIII & $\mathrm{PhNH}_{3}{ }^{+} \rightleftarrows \mathrm{PhNH}_{2}+\mathrm{H}^{+}$ & $\mathrm{H}_{2} \mathrm{O}$ & $\mathrm{p} K_{\mathrm{a}}$ & 4.87 & 25 & 6.64 \\
\hline $\mathrm{IX}$ & $\mathrm{PhNO}_{2} \mathrm{H}^{\cdot} \rightleftarrows \mathrm{PhNO}_{2} \cdot{ }^{-}+\mathrm{H}^{+}$ & $\mathrm{H}_{2} \mathrm{O}$ & $\mathrm{p} K_{\mathrm{a}}$ & 3.2 & 26 & 4.37 \\
\hline$x$ & $\mathrm{PhNOH}^{\cdot} \rightleftarrows \mathrm{PhNO}^{\cdot-}+\mathrm{H}^{+}$ & $\mathrm{H}_{2} \mathrm{O}$ & $\mathrm{p} K_{\mathrm{a}}$ & 11.7 & 27 & 15.96 \\
\hline
\end{tabular}
and standard reaction Gibbs energies (in kcal / mol) calculated from experimental data using formulas (1) or (2). 
To minimize the negative influence of small frequencies to thermodynamic data, molecular partition functions were calculated using the quasiharmonic oscillator approximation. ${ }^{[30]}$ All calculations were performed using Gaussian09, Revision D.01. ${ }^{[31]}$

Theoretical standard reaction Gibbs energies for the reduction reactions relative to the SHE were calculated by the formula

$$
\Delta_{\text {red }} G_{\text {calc }}^{\circ}(s)=G_{\text {calc }}^{\circ}(R, s)-G_{\text {calc }}^{\circ}(\mathrm{O}, s)-n \Delta_{\text {red }} G_{\text {abs }}^{\circ}(\mathrm{SHE})
$$

where $G_{\text {calc }}^{\circ}(R, s)$ and $G_{\text {calc }}^{\circ}(O, s)$ are theoretical standard Gibbs energies of reduced and oxidized reagent in solvent $s, n$ number of exchanged electrons, and $\Delta_{\text {red }} G_{\text {abs }}^{\circ}(\mathrm{SHE})$ standard reaction Gibbs energy equivalent to the absolute value of $E^{\circ}(\mathrm{SHE})$.

Theoretical standard reaction Gibbs energies for the deprotonation equilibria were calculated by the formula

$$
\Delta_{\mathrm{r}} G_{\text {calc }}^{\circ}(a q)=G_{\text {calc }}^{\circ}\left(\mathrm{A}^{-}, a q\right)+G_{\text {exp }}^{\circ}\left(\mathrm{H}^{+}, a q\right)-G_{\text {calc }}^{\circ}(H \mathrm{~A}, a q)
$$

where $G_{\exp }^{\circ}\left(\mathrm{H}^{+}, a q\right)$ is the experimental value of the standard Gibbs energy of proton in water $(-270.3 \mathrm{kcal} / \mathrm{mol}),{ }^{[32]}$ also used for the calculation of standard reaction Gibbs energy of the nitrosobenzene to phenylhydroxyamine reduction (reaction VI, Table 1).

\section{RESULTS AND DISCUSSION}

Fourteen commonly used functionals were tested. Some of them were chosen because they have been previously used for the similar calculations, some because of our good experience with them, and the rest because of their increasing popularity. ${ }^{[33]}$ Møller-Plesset calculations were also performed, but due to the excessive spin contaminations for the radical species, the approach was dropped from further considerations. We also examined the influence of increasing basis sets size to the results, finally settling with the Pople's $6-311+G(2 d f, 2 p)$. While smaller basis sets gave noticeably inferior results, larger Dunning's augmented correlation consistent basis sets (up to aug-cc-pVQZ) gave marginally better results, at a significant expense of the calculation efficiency. The DFT results were compared against the results of two efficient composite methods for computing accurate energies, CBS-QB3 and CBS-APNO. Required standard solvation Gibbs energies $\left(\Delta_{\mathrm{sol}} G^{\circ}\right)$ of participating species were calculated at M06-2X/6-311+ $\mathrm{G}(2 \mathrm{df}, 2 \mathrm{p})$-SMD level of theory.

Table 2. Differences between theoretical and experimental standard reaction Gibbs energies (in $\mathrm{kcal} / \mathrm{mol}$ ), calculated using equations (3) and (4) at DFT/6-311+G(2df,2p)-SMD or CBS-X level of theory. Solution-phase CBS-X values were calculated from

\begin{tabular}{|c|c|c|c|c|c|c|c|c|c|c|c|c|c|c|c|}
\hline DFT & I & II & III & IV & V & $\mathrm{VI}^{(\mathrm{a})}$ & VIII & $\mathrm{VIII}^{(\mathrm{a})}$ & IX & $x$ & $\operatorname{avg}^{(b)}$ & $\operatorname{stdev}^{(b)}$ & $R^{2(\mathrm{c})}$ & stdev(c) & $\mathrm{a}_{0}{ }^{(\mathrm{c})}$ \\
\hline B2PLY & 5.43 & 4.70 & 8.43 & 9.78 & 7.73 & -7.23 & 5.22 & 5.59 & 3.47 & 0.33 & 5.6 & 2.8 & 0.79 & 4.8 & 6.5 \\
\hline B3LYP & -1.47 & -2.20 & 2.92 & 4.97 & 2.91 & -1.18 & 3.88 & 5.15 & 4.09 & 1.87 & 2.5 & 2.6 & 0.98 & 1.4 & 5.3 \\
\hline B97D & 2.30 & 1.73 & 6.81 & 7.71 & 5.70 & -3.58 & -1.73 & 2.69 & 5.51 & 3.33 & 3.8 & 2.9 & 0.88 & 3.7 & 4.3 \\
\hline B98 & 0.27 & -0.43 & 3.48 & 6.45 & 4.39 & -0.93 & 2.95 & 3.77 & 4.79 & 3.41 & 3.2 & 2.1 & 0.96 & 1.9 & 4.9 \\
\hline M06-2X & -0.62 & -1.39 & 1.48 & 6.11 & 2.93 & -1.95 & 10.35 & 6.08 & 2.60 & 0.06 & 3.1 & 3.8 & 0.89 & 2.9 & 6.3 \\
\hline M11 & -2.07 & -2.85 & -0.44 & 4.52 & 2.37 & -0.10 & 9.77 & 6.43 & 0.44 & -0.67 & 1.9 & 4.2 & 0.88 & 3.1 & 5.4 \\
\hline M11L & 0.94 & 0.59 & 5.62 & 4.93 & 2.98 & 1.14 & 3.16 & 6.81 & 3.78 & 3.65 & 3.6 & 2.0 & 0.99 & 1.1 & 5.7 \\
\hline mPW1B95 & 2.56 & 1.91 & 5.49 & 8.48 & 6.40 & -5.97 & 5.02 & 5.22 & 3.60 & 2.21 & 4.5 & 2.2 & 0.87 & 3.5 & 6.2 \\
\hline mPW2PLYP & 4.38 & 3.67 & 7.11 & 9.13 & 7.05 & -6.21 & 5.81 & 5.61 & 3.06 & 0.71 & 5.2 & 2.5 & 0.83 & 4.2 & 6.3 \\
\hline mPWB1K & 0.55 & 1.47 & 4.30 & 8.28 & 6.17 & -2.95 & 5.99 & 4.42 & 4.79 & 3.66 & 4.4 & 2.4 & 0.92 & 2.7 & 6.2 \\
\hline PBEO & 0.32 & -0.30 & 3.53 & 5.63 & 3.57 & -2.32 & 3.63 & 4.92 & 3.69 & 2.49 & 3.1 & 2.0 & 0.97 & 1.6 & 5.1 \\
\hline PBE & 0.74 & 0.23 & 5.83 & 6.11 & 4.15 & -9.41 & 2.06 & 6.87 & 1.48 & -0.52 & 3.0 & 2.8 & 0.81 & 3.9 & 5.6 \\
\hline TPSSh & 1.53 & 0.86 & 5.04 & 6.92 & 4.88 & -3.84 & 1.21 & 3.15 & 4.53 & 3.23 & 3.5 & 2.0 & 0.92 & 2.8 & 4.6 \\
\hline$\omega B 97 X-D$ & 0.51 & -0.25 & 2.86 & 6.04 & 3.94 & 2.13 & 4.46 & 2.79 & 4.84 & 3.47 & 3.2 & 2.0 & 0.97 & 1.7 & 4.5 \\
\hline \multicolumn{16}{|l|}{ CBS-X } \\
\hline CBS-QB3 & 2.17 & 1.43 & 4.42 & 7.26 & 5.20 & -1.59 & 8.78 & 3.49 & 1.82 & 1.08 & 4.0 & 2.7 & 0.92 & 2.9 & 5.2 \\
\hline CBS-APNO & 1.39 & 0.65 & 3.64 & 6.83 & 4.77 & -1.15 & 7.69 & 4.50 & 0.77 & 0.79 & 3.4 & 2.7 & 0.93 & 2.7 & 5.0 \\
\hline
\end{tabular}
the corresponding vacuum values and M06-2X/6-311+G(2df,2p)-SMD standard solvation Gibbs energies.

(a) Reaction is reversed relative to the one given in Table 1 (charged species on the product side).

(b) The average value and standard deviation of $\Delta \Delta_{\mathrm{r}} G^{\circ}$, excluding the data for the reaction VI.

(c) Data for the linear correlation $\Delta_{r} G_{\text {calc }}^{\circ}=a_{1}\left(\Delta_{r} G_{\text {exp }}^{\circ}\right)+a_{0}$, excluding the data for the reaction VI. 
In Table 2 are given differences between calculated and experimental standard reaction Gibbs $\left(\Delta \Delta_{\mathrm{r}} G^{\circ}\right)$ energies for the model reactions arranged in such a way that the charged species appear on the right-hand side of the corresponding chemical equation.

Almost all $\Delta \Delta_{\mathrm{r}} G^{\circ}$ values are positive, with the exception of the reaction $\mathbf{V I}$, in which both reactant and product are neutral molecules. The average of all $\Delta \Delta_{\mathrm{r}} G^{\circ}$ values, excluding the ones for the reaction $\mathrm{VI}$, is $4 \mathrm{kcal} / \mathrm{mol}$. Six functionals (B98, M11L, mPW1B95, PBE0, TPSSh and $\omega B$ 97X-D) have smaller standard deviations $(2 \mathrm{kcal} / \mathrm{mol})$ than the others (3-4 kcal/mol). The results obtained with functionals B3LYP, B98, M11L, PBE0 and $\omega B 97 X-D$ correlate well with experimental $\Delta_{\mathrm{r}} G^{\circ}$ values $\left(R^{2}=0.96-0.99\right.$, regression rms error $=1.1-1.9 \mathrm{kcal} / \mathrm{mol})$.

However, both DFT and CBS-X energy differences are systematically lower than the experimental ones. The average value of the constant term for all of the regression lines is $5 \pm 1 \mathrm{kcal} / \mathrm{mol}$. Taking in mind that the charged species appear on the right-hand side of the equations, these results probably indicate the inadequacy of continuum approach to reproduce charged species solvation in polar solvents.

In conclusion, for the preliminary investigation of nitrobenzene to aniline reduction mechanism we suggest the use of B98, M11L, PBE0 or $\omega B$ 97X-D functionals, $6-311+G(2 d f, 2 p)$ basis set and SMD continuum solvation method. For final results it is essential to include better description of solvation of charged species, possibly via a cluster-continuum approach. Both avenues are currently being explored in our laboratory.

Acknowledgment. We gratefully acknowledge the financial support to this work from the Croatian Science Foundation, grant no. 7444, project ORGMOL.

\section{REFERENCES}

[1] G. Booth, Nitro Compounds, Aromatic. Ullmann's Encyclopedia of Industrial Chemistry, John Wiley \& Sons, New York, 2000.

[2] B. A. Donlon, E. Razo-Flores, G. Lettinga, J. A. Field, Biotechnol. Bioeng. 1996, 51, 439.

[3] B. A. Donlon, E. Razo-Flores, J. A. Field, G. Lettinga, Appl. Environ. Microbiol. 1995, 61, 3889.

[4] I. Halasz, I. Biljan, P. Novak, E. Meštrović, J. Plavec, G. Mali, V. Smrečki, H. Vančik, J. Mol. Struct. 2009, 918, 19.

[5] I. Biljan, T. Medančić, M. Kralj, T. Mišić Radić, V. Svetličić, H. Vančik, Croat. Chem. Acta 2013, 86, 83.

[6] H. Vančik, Aromatic C-nitroso Compounds, Springer, NY, 2013.
[7] A. Maganjić, I. Šolić, S. Milovac, I. Halasz, I. Biljan, H. Vančik, J. Phys. Org. Chem. 2014, 27, 177.

[8] G. Russel, E. Geels, F. J. Smentowski, K.-Y. Chang, J. Reynolds, G. Kaupp, J. Am. Chem. Soc. 1967, 89, 3821.

[9] B. Aguilera-Venegas, C. Olea-Azar, V. Arán, J. D. Maya, U. Kemmerling, H. Speiskym F. Mendizábal, Int. J. Electrochem. Sci., 2012, 7, 5837.

[10] L. Núñez-Vergara, M. Bontá, J. C. Sturm, P. A. Navarette, S. Bollo, J. A. Squella, J. Electroanal. Chem. 2001, 506, 48.

[11] V. Brezová, P. Tarábek, D. Dvoranová, A. Staško, S. Biskupič, J. Photoch. Photobio. A 2003, 155, 179.

[12] M. Polášek, F. Tureček, J. Am. Chem. Soc. 2000, 122, 9511.

[13] C. K. Chua, M. Pumera, L. Ruliššek, J. Phys. Chem. C 2012, 116, 4243.

[14] I. Zilberberg, M. Ilchenko, O. Isayev, L. Gorb, J. Leszczynski, J. Phys. Chem. A 2004, 108, 4878.

[15] C. Chambers, G. Hawkins, C. J. Cramer, D. G. Truhlar, J. Phys. Chem. 1996, 100, 16385.

[16] P. Winget, E. J. Weber, C. J. Cramer, D. G. Truhlar, Phys. Chem. Chem. Phys. 2000, 2, 1231.

[17] P. Winget, C. J. Cramer, D. G. Truhlar, Theor. Chem. Acc. 2004, 112, 217.

[18] R. Zubatyuk, L. Gorb, V. Shishkin, M. Quasim, J. Leszczynski, J. Comp. Chem. 2010, 31, 144.

[19] X.-Q. Zhu, C.-H. Wang, J. Org. Chem. 2010, 75, 5037.

[20] M. F. Bento, M. J. Medeiros, M. I. Montenegro, J. Electroanal. Chem. 1993, 345, 273.

[21] D. Meisel, P. Neta, J. Am. Chem. Soc. 1975, 97, 5198.

[22] L. Núñez-Vergara, J. A. Squella, C. Olea-Azar, S. Bollo, P. A. Navarrette-Encina, J. C. Sturm, Electrochim. Acta 2000, 45, 3555.

[23] Z. Chen, Z. Wang, D. Wu, L. Ma, J. Hazard. Mater. 2011, 197, 424.

[24] E. Y. Belayev, L. M. Gornostaev, M. S. Toubis, L. E. Borina, Zh. Obsch. Khim. 1974, 44, 856.

[25] CRC Handbook of Chemistry and Physics, 95 th Edition, CRC Press, 2014-2015.

[26] P. Neta, D. Meisel, J. Phys. Chem. 1976, 80, 519.

[27] K. D. Asmus, G. Beck, A. Hengelein, A. Wigger, Berichte 1966, 70, 869.

[28] A. A. Isse, A. Gennaro, J. Phys. Chem. B 2010, 114, 7894.

[29] A. V. Marenich, C. J. Cramer, and D. G. Truhlar, J. Phys. Chem. B 2009, 113, 6378.

[30] R. F. Ribeiro, A. V. Marenich, C. J. Cramer, D. G. Truhlar, J. Phys. Chem. B 2011, 115, 14556.

[31] Gaussian 09, Revision D.01, M. J. Frisch, G. W. Trucks, H. B. Schlegel, G. E. Scuseria, M. A. Robb, J. R. Cheeseman, G. Scalmani, V. Barone, B. Mennucci, G. A. Petersson, H. Nakatsuji, M. Caricato, X. Li, H. P. 
Hratchian, A. F. Izmaylov, J. Bloino, G. Zheng, J. L. Sonnenberg, M. Hada, M. Ehara, K. Toyota, R. Fukuda, J. Hasegawa, M. Ishida, T. Nakajima, Y. Honda, O. Kitao, H. Nakai, T. Vreven, J. A. Montgomery, Jr., J. E. Peralta, F. Ogliaro, M. Bearpark, J. J. Heyd, E. Brothers, K. N. Kudin, V. N. Staroverov, T. Keith, R. Kobayashi, J. Normand, K. Raghavachari, A. Rendell, J. C. Burant, S. S. Iyengar, J. Tomasi, M. Cossi, N. Rega, J. M. Millam, M. Klene, J. E. Knox, J. B. Cross, V. Bakken, C. Adamo,
J. Jaramillo, R. Gomperts, R. E. Stratmann, O. Yazyev, A. J. Austin, R. Cammi, C. Pomelli, J. W. Ochterski, R. L. Martin, K. Morokuma, V. G. Zakrzewski, G. A. Voth, P. Salvador, J. J. Dannenberg, S. Dapprich, A. D. Daniels, O. Farkas, J. B. Foresman, J. V. Ortiz, J. Cioslowski, and D. J. Fox, Gaussian, Inc., Wallingford CT, 2013.

[32] K. Alongi, G. Shields, Ann. Rep. Comp. Chem. 2010, 6, 113.

[33] http://www.marcelswart.eu/ (01.06.2015.) 